Received Date : 27-Jun-2016

Revised Date : 04-Aug-2016

Accepted Date : 11-Sep-2016

Article type : Original Article

(1)

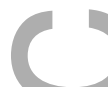

$\infty$

O

Word count:

Abstract: 126

Text: 3,777

Figures \& Tables: 5

(c)

\title{
Medically Documented Suicide Ideation among U.S. Army Soldiers
}

Robert J. Ursano, M.D., Ronald C. Kessler, Ph.D., Murray B. Stein, M.D., M.P.H., James A.

Naifeh, Ph.D., Matthew K. Nock, Ph.D., Pablo A. Aliaga, M.A., Carol S. Fullerton, Ph.D., Gary H. Wynn, M.D., Tsz Hin Hinz Ng, M.P.H., Hieu M. Dinh, B.S., Nancy A. Sampson, B.A., TzuCheg Kao, Ph.D., Michael Schoenbaum, Ph.D., James E. McCarroll Ph.D., M.P.H., Kenneth L. Cox, M.D., M.P.H., Steven G. Heeringa, Ph.D., on behalf of the Army STARRS collaborators

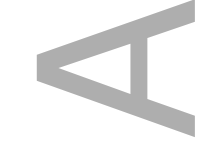

This is the author manuscript accepted for publication and has undergone full peer review but has not been through the copyediting, typesetting, pagination and proofreading process, which may lead to differences between this version and the Version of Record. Please cite this article as doi: $\underline{10.1111 / \text { sltb.12316 }}$

This article is protected by copyright. All rights reserved 
Author Affiliations: Department of Psychiatry, Center for the Study of Traumatic Stress (Ursano, Naifeh, Aliaga, Fullerton, Wynn, Ng, Dinh, McCarroll), and Department of Preventive Medicine and Biometrics (Kao), Uniformed Services University of the Health Sciences, Bethesda, Maryland; Department of Health Care Policy, Harvard Medical School, Boston, Massachusetts (Kessler, Sampson); Department of Psychology, Harvard University, Cambridge, Massachusetts (Nock); University of Michigan, Institute for Social Research, Ann Arbor, Michigan (Heeringa); U.S. Army Public Health Center (Provisional), Aberdeen Proving Ground, Maryland (Cox); Department of Psychiatry and Department of Family Medicine and Public Health (Stein), University of California San Diego, La Jolla, California and VA San Diego Healthcare System, La Jolla, California; National Institute of Mental Health, Bethesda, Maryland (Schoenbaum).

Corresponding Author: Robert J. Ursano M.D., email: robert.ursano@usuhs.edu, Address: Department of Psychiatry, Uniformed Services University of the Health Sciences, 4301 Jones Bridge Road, Bethesda, MD 20814, Phone: 301-295-9797

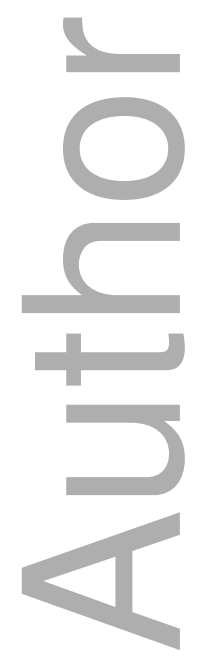

This article is protected by copyright. All rights reserved 


\begin{abstract}
We used administrative data to examine predictors of medically documented suicide ideation among Regular Army soldiers from 2006 through 2009 (n=10,466 ideators, 124,959 control person-months). Enlisted ideators ( $97.8 \%$ of all cases) were more likely than controls to be female, younger, older when entering service, less educated, never or previously deployed, and have a recent mental health diagnosis. Officer ideators were more likely than controls to be female, younger, younger when entering service, never married, and have a recent mental health diagnosis. Risk among enlisted soldiers peaked in the second month of service and declined steadily, whereas risk among officers remained relatively stable over time. Risk of suicide ideation is highest among enlisted soldiers early in Army service, females, and those with a recent mental health diagnosis.
\end{abstract}

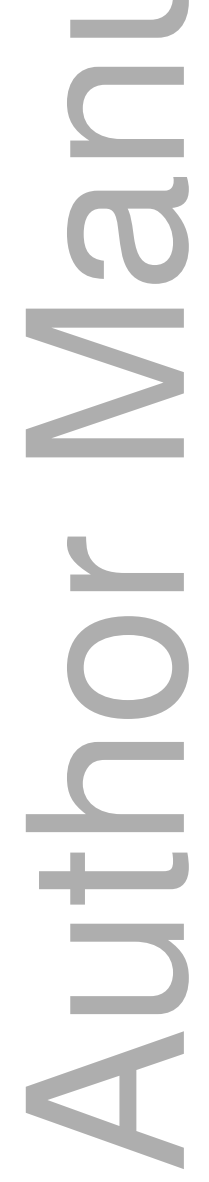

This article is protected by copyright. All rights reserved 
In recent years, there have been several large-scale efforts to understand the sharp increase in fatal(LeardMann et al., 2013; Reger et al., 2015; Schoenbaum et al., 2014) and nonfatal(Nock et al., 2014; Ursano, Kessler, Heeringa, et al., 2015; Ursano, Kessler, Stein, et al., 2015) suicidal behaviors among U.S. military personnel that occurred during the wars in Iraq and Afghanistan. Suicide ideation (SI) is an important outcome as both an indicator of distress and as a predictor of more serious suicidal behavior.(Kessler, Borges, \& Walters, 1999; Nock et al., 2014; Ursano, Heeringa, et al., 2015) The lifetime prevalence of SI is approximately 14\% among active duty Regular Army soldiers.(Nock et al., 2014) The socio-demographic correlates of ideation in service members, including female gender, younger age, and non-Hispanic white race and ethnicity(Nock et al., 2014; Ursano, Kessler, Heeringa, et al., 2015) are consistent with those of the U.S. general population.(Borges, Angst, Nock, Ruscio, \& Kessler, 2008; Kessler, Berglund, Borges, Nock, \& Wang, 2005). Risk of attempting or dying by suicide is higher among enlisted soldiers in the their first tour of duty,(Gilman et al., 2014; Ursano, Kessler, Stein, et al., 2015) but the relationship of time in service with SI is not yet known. Although the influence of deployment on adverse mental health outcomes is well supported,(Bray et al., 2010; Gadermann et al., 2012; Jacobson et al., 2008; Shen, Arkes, \& Williams, 2012; Wells et al., 2010) the association of deployment with suicidal thoughts and behaviors has generated inconsistent results.(Bryan et al., 2015) Prior mental disorders are a robust predictor of both fatal(Black, Gallaway, Bell, \& Ritchie, 2011) and nonfatal(Ursano, Kessler, Stein, et al., 2015) suicidal behaviors in service members, findings in line with a large body of civilian research.(Harris \& Barraclough, 1997; Nock, Hwang, Sampson, \& Kessler, 2010)

Risk factors for SI differ from those for other suicidal behavior.(Kessler et al., 2005; Nock \& Kazdin, 2002; Nock et al., 2014; Ursano, Heeringa, et al., 2015) Mood disorder is often linked to suicide. However, only a small minority of people with mood disorders make a suicide attempt, and only about $2 \%$ die by suicide.(Bostwick \& Pankratz, 2000) In contrast, approximately one-third of suicide ideators go on to make an attempt.(Kessler et al., 1999; Nock et al., 2014; Ursano, Heeringa, et al., 2015) Despite this, surprisingly few studies have focused on understanding and predicting the occurrence of SI in its own right. Ideators already identified by the healthcare system provide an opportunity for preventive interventions.

Our aim is to provide the first comprehensive analysis of medically documented SI in the U.S. Army during the wars in Iraq and Afghanistan. Using data from the Army Study to Assess 
Risk and Resilience in Servicemembers (Army STARRS; www.armystarrs.org),(Kessler et al., 2013; Ursano et al., 2014) we examined socio-demographic, service-related, and mental health predictors of SI from 2006 through 2009. This study includes a large, representative, multi-year sample of active duty soldiers serving during wartime. It is an important addition to retrospective self-report data on SI from recent Army STARRS survey research, which did not include soldiers in basic training or those who were currently deployed.(Nock et al., 2014) Administrative medical records are a feasible way to study SI using existing data, in which no additional assessment is required. Furthermore, ideators who are already identified by the military healthcare system provide an opportunity to intervene and prevent more serious outcomes. In contrast to the growing number of findings based on survey research, we are not aware of any studies that have systematically examined medically documented suicide ideation among active duty service members.

\section{Sample}

\section{METHODS}

The Army STARRS Historical Administrative Data Study (HADS) integrates 38 Army/DoD administrative data systems.(Kessler et al., 2013) Creation and analysis of this consolidated and deidentified data system were approved by the institutional review boards of the Uniformed Services University, University of Michigan Institute for Social Research, University of California, San Diego, and Harvard Medical School. In this longitudinal, retrospective cohort study, we focused on records for the 778,041 Regular Army soldiers (excluding activated Army National Guard and Army Reserve) on active duty from January 1, 2006 through December 31, 2009. There were 10,466 soldiers ( $n=10,232$ enlisted, 234 commissioned and warrant officers) with documented SI during this time (excluding those with documentation of other suicidal behaviors). Data were analyzed using a discrete-time survival framework with person-month as the unit of analysis,(Willett \& Singer, 1993) such that each month in the career of a soldier was treated as a separate observational record. Given that discrete-time survival coefficients can be estimated without bias when control person-months are randomly subsampled and weighted using the logic of case-control analysis,(Schlesselman, 1982) we reduced computational intensity by selecting from the population an equal-probability 1:200 sample of 124,959 control person-months ( $n=104,369$ enlisted, 20,590 officer) stratified by gender, rank, time in service, deployment status (never, currently, previously), and historical 
time. The control person-months excluded all soldiers with documented SI or other nonfatal suicidal event (e.g., suicide attempt)(Ursano, Kessler, Heeringa, et al., 2015) and person-months in which a soldier died. Control person-months were assigned a weight of 200 to adjust for under-sampling.

\section{Measures}

Administrative documentation of SI during Army service was identified using: records from the Department of Defense Suicide Event Report (DoDSER);(Gahm et al., 2012) and ICD9-CM V62.84 diagnostic codes (indicating SI) from healthcare encounter information from military and civilian treatment facilities, combat operations, and aeromedical evacuations. We excluded soldiers who ever attempted or completed suicide. For soldiers documented to have had SI more than once, we selected the first record using a hierarchical classification scheme that prioritized DoDSER records.(Ursano, Kessler, Heeringa, et al., 2015) Using administrative person-month records dating to the year 2000 (or first entry into the Army for those who began service later), we constructed indicators for temporally prior predictor variables, including sociodemographics, time in service, deployment status, and mental health diagnosis (Appendix A, www.armystarrs.org/publications). The indicator variable for previous mental health diagnosis was created from ICD-9-CM mental disorder codes (e.g., major depression, posttraumatic stress disorder, personality disorders), excluding postconcussion syndrome, tobacco use disorder, and supplemental V-codes (e.g., stressors/adversities, marital problems) (Appendix B). Recency of diagnosis was determined based on the number of months between the most recent diagnostic record and the SI record (cases) or sampled person-month (controls).

\section{Analysis methods}

Analyses were conducted separately for enlisted soldiers and officers owing to their different socio-demographic profiles, Army training and career experiences,(Segal \& Segal, 2004) and risk of mental health problems,(Bray et al., 2009; Lapierre, Schwegler, \& LaBauve, 2007; Smith et al., 2008) suicide attempt,(Ursano, Kessler, Stein, et al., 2015) and suicide death.(Gilman et al., 2014; Hyman, Ireland, Frost, \& Cottrell, 2012) Logistic regression analyses examined multivariate associations of socio-demographics (gender, age at entry into Army service, current age, race, education, and marital status) with SI, followed by separate models evaluating incremental predictive effects of time in service (1-2 years, 3-4 years, 5-10 years, >10 years), deployment status (never deployed [ND], currently deployed [CD], previously deployed 
[PD]), and presence/recency of mental health diagnosis (none vs. 1, 2-3, 4-12, and 13+ months since most recent diagnosis). Logistic regression coefficients were exponentiated to obtain oddsratios (OR) and 95\% confidence intervals (CI). Final model coefficients were used to generate standardized estimates of risk(Roalfe, Holder, \& Wilson, 2008) (number of suicide ideators per 100,000 person-years) for each category of each predictor under the model assuming other predictors were at their sample-wide means. The number of suicide ideators per 100,000 personyears is the number of ideators we would expect out of 100,000 soldiers followed for a year. For example, the total Regular Army suicide rate during $2004-2009$ was 18.5 per 100,000 personyears (Gilman et al., 2014). Based on evidence that the rate of SI in the Army increased during the wars in Iraq and Afghanistan,(Ursano, Kessler, Heeringa, et al., 2015) a separate dummy predictor was included in each logistic regression to control for calendar month and year. Coefficients of other predictors can consequently be interpreted as averaged within-month associations based on the assumption that effects of other predictors do not vary over time. To further examine associations between time in service and risk of SI, we generated separate discrete-time hazard functions for enlisted soldiers and officers. These hazard functions were used to estimate risk of ideation in each month since entering Army service (suicide ideators per 100,000 person-months).

\section{RESULTS}

Enlisted soldiers comprised $83.5 \%$ of active duty Regular Army soldiers, $97.8 \%$ of all suicide ideators $(n=10,232)$, and had an overall SI rate of 587.9 per 100,000 person-years $(95 \%$ CI: 576.9-599.8). Officers (commissioned and warrant officers) made up $16.5 \%$ of the Regular Army and $2.2 \%$ of ideators $(n=234)$, with an overall rate of 68.2 per 100,000 person-years $(95 \%$ CI: 60.0-77.5) (Tables 1 and 2).

\section{Socio-demographic characteristics}

Among enlisted soldiers, higher odds of SI were observed in those who were female $(\mathrm{OR}=1.6$ [95\% CI: 1.5-1.7]); younger (age <21 years, OR=3.9 [95\% CI: 3.6-4.3]); entered the Army at age $\geq 25(\mathrm{OR}=1.6$ [95\% CI: 1.5-1.8]); and had less than a high school education $(\mathrm{OR}=1.8$ [95\% CI: 1.7-1.9]). Odds of SI were lower among non-Whites (OR=0.7-0.9) (Table 1).

Among officers, higher odds of SI were observed in those who were female $(\mathrm{OR}=2.3$ [95\% CI: 1.7-3.1]), entered the Army at <21 years of age (OR=1.8 [95\% CI: 1.3-2.4]). Lower 
odds of SI were observed for those $\geq 40(\mathrm{OR}=0.6$ [95\% CI: 0.4-0.9]) and never married (OR=0.6 [95\% CI: 0.4-0.9]) (Table 2).

Enlisted females had more than six times the risk of female officers (rate ratio $[R R]=6.5$

[95\% CI: 5.1-8.3]). Having a current age of $\geqq 40$ was protective for both enlisted and officers, but risk among enlisted personnel in this age group was more than four times higher than officers $(\mathrm{RR}=4.1[95 \% \mathrm{CI}: 3.0-5.6])$.

\section{Time in service}

After adjusting for socio-demographics, enlisted soldiers in their first four years of service had higher odds of suicide ideation (1-2 years, OR=2.2 [95\% CI: 2.0-2.4]; 3-4 years, $\mathrm{OR}=1.4$ [95\% CI: 1.3-1.5]) than those with 5-10 years of service; those serving for $>10$ years had lower odds (OR=0.6 [95\% CI: 0.5-0.7]) (Table 3). Additional pairwise analyses revealed differences across all categories of time in service among enlisted soldiers $\left(\chi_{1}^{2}=82.6-419.4\right.$, $p<0.0001$ for all analyses). Time in service was not associated with ideation among officers $\left(\chi_{3}^{2}=6.8, p=0.08\right)$ (Table 4). Enlisted soldiers in their first two years of service had the highest standardized risk, which was more than 10 times that of officers in the same category $(\mathrm{RR}=10.6$ [95\% CI: 7.5-15.1]).

A discrete-time hazard model (Figure 1) demonstrated greatly elevated risk among enlisted soldiers during their first year in the Army (average risk: 115.7 per 100,000 personmonths), with risk peaking in the second month of service (182.2 per 100,000 person-months), followed by a sharp decrease to 79.2 per 100,000 person-months. Rising again to 127.5 per 100,000 person-months by the sixth month of service, risk of SI then decreased substantially to a mean of 66.3 per 100,000 person-months during the second year of service, followed by a gradual decline to a mean of 51.1 per 100,000 person-months during the third and fourth years of

service. For officers, risk remained relatively stable across the first four years of service (overall mean 4.6 per 100,000 person-months).

\section{Deployment status}

We found higher odds of SI among ND (OR=3.9 [95\% CI: 3.6-4.2]) and PD (OR=3.5 [95\% CI: 3.2-3.8]) enlisted soldiers than among those CD, adjusting for socio-demographic variables (Table 3). ND enlisted soldiers also had significantly higher odds than those PD in an additional pairwise analysis (OR=1.1 [95\% CI: 1.1-1.2]). Deployment status was not associated with ideation among officers (Table 4). ND enlisted soldiers accounted for a similar proportion 
of their respective population as ND officers (36.2\% vs. $30.7 \%$ ), but had a standardized risk more than 11 times higher ( $R R=11.6$ [95\% CI: 9.1-14.8]). Although a smaller proportion of enlisted soldiers were PD compared to officers ( $38.7 \%$ vs. $48.2 \%$ ), their standardized risk of SI was more than eight times higher ( $R R=8.8$ [95\% CI: 7.4-10.5]).

\section{Mental health diagnosis}

Among those with SI, $58.9 \%$ of enlisted soldiers and $73.1 \%$ officers had a previous mental health diagnosis. Among ideators with a history of mental health diagnosis, $59.1 \%$ of enlisted soldiers and $57.3 \%$ of officers most recently had a diagnoses in the month prior to ideation. Adjusting for socio-demographics, enlisted soldiers with a mental health diagnosis in the previous month had the highest odds of ideation ( $\mathrm{OR}=14.4$ [95\% CI: 13.7-15.0]) compared to those without a diagnosis, with odds decreasing as the time since most recent diagnosis increased from 2-3 months $(\mathrm{OR}=5.0$ [95\% CI: 4.7-5.4]) to $\geq 13$ months (OR=1.3 [95\% CI: 1.2-1.4]) (Table 3). Officers with a mental health diagnosis in the previous month similarly had the greatest likelihood of SI (OR=74.0 [95\% CI: 52.9-103.6]), and longer intervals resulted in increasingly smaller ORs, ranging from 13.4 (95\% CI: 7.7-23.1) for 2-3 months to 3.8 (95\% CI: 2.4-6.0) for $\geq 13$ months (Table 4). The elevated standardized risk in the month after the diagnosis was nearly three times higher for enlisted soldiers than officers ( $\mathrm{RR}=2.8$ [95\% CI: 2.3-3.4).

\section{DISCUSSION}

Using comprehensive U.S. Army and DoD administrative data, this study identified active duty Regular Army soldiers at greatest risk of documented SI from 2006 through 2009. These ideators have been identified by the medical care system and, importantly, are therefore available for intervention. Consistent with research on suicide attempts(Ursano, Kessler, Stein, et al., 2015) and suicide deaths(Gilman et al., 2014) among soldiers, risk of ideation was far greater in enlisted personnel than officers. Enlisted soldiers comprised approximately $83 \%$ of the Army,

but nearly $98 \%$ of suicide ideators, with an overall rate of 587.9 per 100,000 person-years versus 68.2 per 100,000 person-years for officers. As in the military, most civilian data on the epidemiology of SI come from survey research,(Nock et al., 2008) making accurate comparisons of medically documented ideation rates between military and civilian populations virtually impossible. Medically documented ideation among U.S. civilians is not captured by comprehensive administrative data systems that can be integrated across medical facilities.

The most consistent predictors of ideation, regardless of rank, were being female, 
younger age and a history of mental health diagnosis, supporting previous civilian (Borges et al., 2008; Kessler et al., 2005; Nock et al., 2010) and active duty military (Nock et al., 2014) research on self-reported SI. Female enlisted soldiers were $60 \%$ more likely than males to have documented ideation, whereas female officers were more than twice as likely. However, females comprised only $17.8 \%$ of ideation cases among enlisted soldier and $26.5 \%$ of cases among officers, supporting the important fact that Army clinicians are far more likely to treat male ideators. The higher likelihood of SI among females is consistent with survey data from new soldiers, which found that females entering the Army are about $40 \%$ more likely than males to report a pre-enlistment history of ideation (Ursano, Heeringa, et al., 2015). In addition to this differential pre-enlistment vulnerability, female soldiers may experience unique stressors during military service (Street, Vogt, \& Dutra, 2009). Males and females may also experience different challenges in acclimating to the military culture and environment, although this has yet to be examined systematically.

Enlisted soldiers and officers varied on a number of socio-demographic and Army career predictors. In particular, time in service and deployment status were significantly associated with ideation among enlisted soldiers, but not among officers.

Less experienced enlisted personnel in their first two years of service are more than twice as likely to experience documented SI relative to soldiers in their fifth year and beyond. Risk among enlisted soldiers peaked in the second month of service (182.2 per 100,000 personmonths), around the time soldiers are completing basic training and transitioning to more specialized training. Although further research is needed to better understand this period of elevated risk, it may reflect the stressors of basic training (e.g., high physical and mental performance demands, separation from family and friends, loss of control over one's day-to-day life) and pre-existing vulnerabilities. Army STARRS survey research has found that a substantial proportion of soldiers entering the Army report a pre-enlistment history of mental health disorders (39\%),(Rosellini et al., 2015) as well as SI (14.1\%), plans (2.3\%), and attempts (1.9\%).(Ursano, Heeringa, et al., 2015) Soldiers with a pre-military history of suicidality may be at risk for more serious suicidal outcomes during and after service.(Bryan, Bryan, Ray-Sannerud, Etienne, \& Morrow, 2014) Importantly, enlisted soldiers in the early months of training were similarly found to be at risk of attempting suicide,(Ursano, Kessler, Stein, et al., 2015) suggesting that early screening and documentation of suicidal thoughts could provide an 
opportunity to prevent more serious outcomes and improve population health.

SI was less likely among currently deployed enlisted soldiers than those never or previously deployed, consistent with findings on attempted suicide (6). This association was not observed among officers. Deployment is associated with a variety of negative mental health outcomes,(Bray et al., 2010; Gadermann et al., 2012; Jacobson et al., 2008; Shen et al., 2012; Wells et al, 2010) including risk of suicide death.(Gilman et al., 2014) However, specific combat experiences while deployed may be more important than deployment, per se, in understanding suicide risk.(Bryan et al., 2015) Although reduced risk of SI during deployment could be influenced by a number of factors, including pre-deployment mental health screening (i.e. a healthy deployed soldier effect),(Warner, Appenzeller, Parker, Warner, \& Hoge, 2011) it is also possible that medical documentation and coding procedures differ during deployment. To the extent that changes in coding procedures for SI occur in theater, this could artificially reduce the observed risk in currently deployed soldiers. Linked survey and administrative data would help clarify this by allowing for a comparison of self-reported and medically documented ideation among soldiers across the entire deployment cycle. Additional research is also needed to address broader questions regarding the role of deployment status in fatal versus non-fatal suicidal behaviors.

Consistent with the well-documented association between mental health diagnoses and suicidal outcomes,(Black et al., 2011; Harris \& Barraclough, 1997; Nock et al., 2013; Nock et al., 2010; Ursano, Kessler, Stein, et al., 2015) we found that a history of a mental health diagnosis was present in 58.9-73.1\% of ideators. Recency of diagnosis was particularly important, with nearly $60 \%$ of ideators having a diagnosis recorded in the month before ideation was documented. These findings were very similar to research on attempted suicide among soldiers,(Ursano, Kessler, Stein, et al., 2015) suggesting that a large proportion of at-risk soldiers had a recent encounter with the healthcare system in which mental and/or behavioral health difficulties were noted. Although suicide risk assessment and prevention are ongoing challenges in any healthcare system, these recent encounters provide opportunities for intervention. Further research that examines the influence of specific diagnoses on risk of future SI, and particularly transitions from ideation to attempt,(Nock et al., 2010; Nock et al., in press) as well as research on how ideation may be affected by the type and continuity of care can further refine our 
understanding and opportunities for intervention.(King et al., 2001; Luoma, Martin, \& Pearson, 2002)

The current study is informed and limited by its exclusive focus on medically documented SI. The fact that these cases came to the attention of clinicians may reflect a number of factors, including severity of SI, effectiveness of health screening and referral procedures, vigilance on the part of commanders who ordered the soldier to seek care, the soldier's willingness to access treatment, thorough assessment of suicide risk by clinicians in either general medical and specialty care, and the soldier's openness in reporting SI. Future longitudinal studies of Army STARRS will examine self-reported SI which is and is not documented in medical records. Civilian research suggests that most people with a history of SI have never sought treatment,(Bruffaerts et al., 2011) and recent survey research indicates that the majority of soldiers who report a mental disorder are not currently receiving mental health treatment.(Colpe et al., 2015) In addition, Army chaplains and other non-medical parts of the system are likely to hear reports of SI that may not make their way into administrative records. Thus, administrative records capture a particular subset of soldiers who, in spite of any perceived stigma or negative career implications (Hoge \& Castro, 2012), sought medical care (or were referred) and acknowledged that they were considering suicide. Administrative records are also subject to errors in clinician diagnosis or medical coding. Although the data in this study cannot speak to the proportion of all soldiers with SI who are captured in administrative medical records, they reveal that the Army health care system was successful in documenting a substantial number at-risk soldiers. This may reflect the Army's efforts to improve mental health screening and SI reporting mechanisms, decreasing stigma (Warner, Appenzeller, Mullen, Warner, \& Grieger, 2008), and perhaps soldiers' increasing trust in mental health care. How people feel when they interact with clinicians, particularly their level of trust, may be key in the ability to detect SI (Ganzini et al., 2013). For soldiers with SI who have not been identified by clinicians, the administrative data included in this study could be used to develop algorithms to assist in risk detection (Kessler et al., 2016; Kessler et al., 2015; McCarthy et al., 2015).

There are several other noteworthy limitations. First, our findings may not generalize to the Army population in other time periods. Second, our focus on active duty Regular Army soldiers does not address risk and protective factors in Army National Guard and Reserve soldiers, or among veterans who have separated from the Army. We will include these 
populations in future Army STARRS analyses. Third, the predictors examined in the current study are not exhaustive. Future studies should examine the association of SI with other servicerelated characteristics (e.g., military occupational specialty, history of promotion and demotion) and mental health indicators (e.g., number and types of psychiatric diagnoses, treatment history) documented in administrative records, as well as predictors derived from Army STARRS prospective survey data. Lastly, it is important to note that the observed differences across time in service and deployment status are not evidence of within-person changes in risk over time, as the composition of these groups is affected by the non-random nature of Army attrition and deployment.(Hoge, Auchterlonie, \& Milliken, 2006; Ireland, Kress, \& Frost, 2012; Warner et al., 2011)

\section{Conclusion}

From 2006 through 2009, most cases of medically documented SI in the U.S. Army occurred among enlisted soldiers in their first tour of duty. Risk was particularly elevated among enlisted soldiers during the initial months of training, and among soldiers with a metal health diagnosis recorded during a recent healthcare encounter. Given apparent similarities between our findings on SI and recently published evidence on suicide attempts, it is important for future studies to examine how risk may differ across suicide-related outcomes of increasing severity.

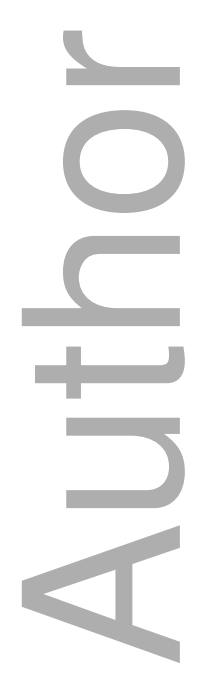

This article is protected by copyright. All rights reserved 


\section{ACKNOWLEDGEMENTS}

Conflict of Interest Disclosures: Kessler has been a consultant over the past three years for J \& J Wellness \& Prevention, Inc., Lake Nona Institute, Ortho-McNeil Janssen Scientific Affairs, Sanofi- Aventis Groupe, Shire US Inc., and Transcept Pharmaceuticals Inc. and has had research support for his epidemiological studies over this time period from EPIQ, and Sanofi-Aventis Groupe, and Walgreens Co. Kessler owns 25\% share in DataStat, Inc. Stein has been a consultant for Healthcare Management Technologies, Janssen Pharmaceuticals, Pfizer, and Tonix Pharmaceuticals. The remaining authors report nothing to disclose.

Funding/Support: Army STARRS was sponsored by the Department of the Army and funded under cooperative agreement number U01MH087981 with the U.S. Department of Health and Human Services, National Institutes of Health, National Institute of Mental Health (NIH/NIMH). The contents are solely the responsibility of the authors and do not necessarily represent the views of the Department of Health and Human Services, NIMH, the Department of the Army, or the Department of Defense.

Role of the Funder/Sponsor: As a cooperative agreement, scientists employed by NIMH (Colpe and Schoenbaum) and Army liaisons/consultants (COL Steven Cersovsky, MD, MPHUSAPHC and Kenneth Cox, MD, MPH USAPHC) collaborated to develop the study protocol and data collection instruments, supervise data collection, interpret results, and prepare reports. Although a draft of this manuscript was submitted to the Army and NIMH for review and comment prior to submission, this was with the understanding that comments would be no more than advisory.

Group Information: The Army STARRS Team consists of Co-Principal Investigators: Robert J. Ursano, MD (Uniformed Services University of the Health Sciences) and Murray B. Stein, MD, MPH (University of California San Diego and VA San Diego Healthcare System); Site Principal Investigators: Steven Heeringa, PhD (University of Michigan) and Ronald C. Kessler, PhD (Harvard Medical School); National Institute of Mental Health (NIMH) collaborating scientists: Lisa J. Colpe, PhD, MPH and Michael Schoenbaum, PhD; Army liaisons/consultants: COL Steven Cersovsky, MD, MPH (USAPHC) and Kenneth Cox, MD, MPH (USAPHC). 
Other team members were: Pablo A. Aliaga, MS (Uniformed Services University of the Health Sciences); COL David M. Benedek, MD (Uniformed Services University of the Health Sciences); K. Nikki Benevides, MA (Uniformed Services University of the Health Sciences); Paul D. Bliese, PhD (University of South Carolina); Susan Borja, PhD (NIMH); Evelyn J. Bromet, PhD (Stony Brook University School of Medicine); Gregory G. Brown, PhD (University of California San Diego); Laura Campbell-Sills, PhD (University of California San Diego); Catherine L. Dempsey, PhD, MPH (Uniformed Services University of the Health Sciences); Carol S. Fullerton, $\mathrm{PhD}$ (Uniformed Services University of the Health Sciences); Nancy Gebler, MA (University of Michigan); Robert K. Gifford, PhD (Uniformed Services University of the Health Sciences); Stephen E. Gilman, ScD (Harvard School of Public Health); Marjan G. Holloway, PhD (Uniformed Services University of the Health Sciences); Paul E. Hurwitz, MPH (Uniformed Services University of the Health Sciences); Sonia Jain, PhD (University of California San Diego); Tzu-Cheg Kao, PhD (Uniformed Services University of the Health Sciences); Karestan C. Koenen, PhD (Columbia University); Lisa Lewandowski-Romps, PhD (University of Michigan); Holly Herberman Mash, PhD (Uniformed Services University of the Health Sciences); James E. McCarroll, PhD, MPH (Uniformed Services University of the Health Sciences); James A. Naifeh, PhD (Uniformed Services University of the Health Sciences); Tsz Hin Hinz Ng, MPH (Uniformed Services University of the Health Sciences); Matthew K. Nock, PhD (Harvard University); Rema Raman, PhD (University of California San Diego); Holly J. Ramsawh, PhD (Uniformed Services University of the Health Sciences); Anthony Joseph Rosellini, PhD (Harvard Medical School); Nancy A. Sampson, BA (Harvard Medical School); LCDR Patcho Santiago, MD, MPH (Uniformed Services University of the Health Sciences); Michaelle Scanlon, MBA (NIMH); Jordan W. Smoller, MD, ScD (Harvard Medical School); Amy Street, PhD (Boston University School of Medicine); Michael L. Thomas, PhD (University of California San Diego); Patti L. Vegella, MS, MA (Uniformed Services University of the Health Sciences); Leming Wang, MS (Uniformed Services University of the Health Sciences); Christina L. Wassel, PhD (University of Pittsburgh); Simon Wessely, FMedSci (King's College London); Christina L. Wryter, BA (Uniformed Services University of the Health Sciences); Hongyan Wu, MPH

This article is protected by copyright. All rights reserved 
(Uniformed Services University of the Health Sciences); LTC Gary H. Wynn, MD (Uniformed Services University of the Health Sciences); Alan M. Zaslavsky, PhD (Harvard Medical School); and Bailey G. Zhang, MS (Uniformed Services University of the Health Sciences). Disclaimer: The contents are solely the responsibility of the authors and do not necessarily represent the views of the US Department of Health and Human Services, the National Institute of Mental Health, the US Department of the Army, or the US Department of Defense.

Additional Contributors: John Mann, Maria Oquedo, Barbara Stanley, Kelly Posner, Kohn Kelp, Dept of Psychiatry Columbia U, College of Physicians and Surgeons, and NY State Psychiatric Institute contributed to the early stages of the US Army STARRS development.

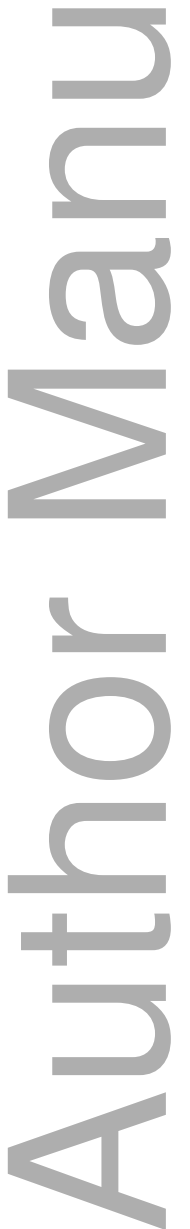




\section{REFERENCES}

Black, S. A., Gallaway, M. S., Bell, M. R., \& Ritchie, E. C. (2011). Prevalence and risk factors associated with suicides of army soldiers 2001-2009. Military Psychology, 23, 433-451.

Borges, G., Angst, J., Nock, M. K., Ruscio, A. M., \& Kessler, R. C. (2008). Risk factors for the incidence and persistence of suicide-related outcomes: A 10-year follow-up study using the National Comorbidity Surveys. Journal of Affective Disorders, 105, 25-33.

Bostwick, J. M., \& Pankratz, V. S. (2000). Affective disorders and suicide risk: A reexamination. American Journal of Psychiatry, 157, 1925-1932.

Bray, R. M., Pemberton, M. R., Hourani, L. L., Witt, M., Olmsted, K. L. R., Brown, J. M., et al. (2009). 2008 Department of Defense Survey of Health Related Behaviors Among Active Duty Military Personnel: A Component of the Defense Lifestyle Assessment Program (DLAP). Research Triangle Park, North Carolina: RTI International.

Bray, R. M., Pemberton, M. R., Lane, M. E., Hourani, L. L., Mattiko, M. J., \& Babeu, L. A. (2010). Substance use and mental health trends among U.S. military active duty personnel: Key findings from the 2008 DoD Health Behavior Survey. Military Medicine, 175, 390-399.

Bruffaerts, R., Demyttenaere, K., Hwang, I., Tat Chiu, W., Sampson, N., Kessler, R. C., et al. (2011). Treatment of suicidal people around the world. British Journal of Psychiatry, 199, 64-70.

Bryan, C. J., Bryan, A. O., Ray-Sannerud, B. N., Etienne, N., \& Morrow, C. E. (2014). Suicide attempts before joining the military increase risk for suicide attempts and severity of suicidal ideation among military personnel and veterans. Comprehensive Psychiatry, 55(3), 534-541.

Bryan, C. J., Griffith, J. H., Pace, B. T., Hinkson, K., Bryan, A. O., Clemans, T. A., et al. (2015). Combat exposure and risk for suicidal thoughts and behaviors among military personnel and veterans: A systematic review and meta-analysis. Suicide and Life-Threatening Behavior, 45(5), 633-649.

Colpe, L. J., Naifeh, J. A., Aliaga, P., Sampson, N. A., Heeringa, S. G., Stein, M. B., et al. (2015). Mental health treatment among soldiers with current mental disorders in the 
Army Study to Assess Risk and Resilience in Servicemembers (Army STARRS). Military Medicine, 180(10), 1041-1051.

Gadermann, A. M., Engel, C. C., Naifeh, J. A., Nock, M. K., Petukhova, M., Santiago, P. N., et al. (2012). Prevalence of DSM-IV major depression among U.S. military personnel: Meta-analysis and simulation. Military Medicine, 177, 47-59.

Gahm, G. A., Reger, M. A., Kinn, J. T., Luxton, D. D., Skopp, N. A., \& Bush, N. E. (2012). Addressing the surveillance goal in the National Strategy for Suicide Prevention: The Department of Defense Suicide Event Report. American Journal of Public Health, 102(Suppl 1), S24-S28.

Ganzini, L., Denneson, L. M., Press, N., Bair, M. J., Helmer, D. A., Poat, J., et al. (2013). Trust is the basis for effective suicide risk screening and assessment in veterans. Journal of General Internal Medicine, 28(9), 1215-1221.

Gilman, S. E., Bromet, E. J., Cox, K. L., Colpe, L. J., Fullerton, C. S., Gruber, M. J., et al. (2014). Socio-demographic and career history predictors of suicide and suicide mortality in the United States Army 2004-2009. Psychological Medicine, 44(12), 2579-2592.

Harris, E. C., \& Barraclough, B. (1997). Suicide as an outcome for mental disorders. A metaanalysis. British Journal of Psychiatry, 170, 205-228.

Hoge, C. W., Auchterlonie, J. L., \& Milliken, C. S. (2006). Mental health problems, use of mental health services, and attrition from military service after returning from deployment to Iraq or Afganistan. Journal of the American Medical Association, 295, $1023-1032$.

Hoge, C. W., \& Castro, C. A. (2012). Preventing suicides in US service members and veterans: Concerns after a decade of war. Journal of the American Medical Association, 308, 671672 .

Hyman, J., Ireland, R., Frost, L., \& Cottrell, L. (2012). Suicide incidence and risk factors in an active duty US military population. American Journal of Public Health, 102(Suppl 1), S138-S146.

Ireland, R. R., Kress, A. M., \& Frost, L. Z. (2012). Association between mental health conditions diagnosed during initial eligibility for military health care benefits and subsequent deployment, attrition, and death by suicide among active duty service members. Military Medicine, 177(10), 1149-1156.

This article is protected by copyright. All rights reserved 
Jacobson, I. G., Ryan, M. A. K., Hooper, T. I., Smith, T. C., Amoroso, P. J., Boyko, E. J., et al. (2008). Alcohol use and alcohol-related problems before and after military combat deployment. Journal of the American Medical Association, 300(6), 663-675.

Kessler, R. C., Berglund, P., Borges, G., Nock, M., \& Wang, P. S. (2005). Trends in suicide ideation, plans, gestures, and attempts in the United States, 1990-1992 to 2001-2003. Journal of the American Medical Association, 293(20), 2487-2495. doi: 10.1001/jama.293.20.2487

Kessler, R. C., Borges, G., \& Walters, E. E. (1999). Prevalence of and risk factors for lifetime suicide attempts in the National Comorbidity Survey. Archives of General Psychiatry, 56(7), 617-626.

Kessler, R. C., Colpe, L. J., Fullerton, C. S., Gebler, N., Naifeh, J. A., Nock, M. K., et al. (2013). Design of the Army Study to Assess Risk and Resilience in Servicemembers (Army STARRS). International Journal of Methods in Psychiatric Research, 22(4), 267-275.

Kessler, R. C., Stein, M. B., Petukhova, M. V., Bliese, P. D., Bossarte, R. M., Bromet, E. J., et al. (2016). Predicting suicides after outpatient mental health visits in the Army Study to Assess Risk and Resilience in Servicemembers (Army STARRS). Molecular Psychiatry, Epub ahead of print.

Kessler, R. C., Warner, C. H., Ivany, C., Petukhova, M. V., Rose, S., Bromet, E. J., et al. (2015). Predicting suicides after psychiatric hospitalization in US Army soldiers: The Army Study to Assess Risk and Resilience in Servicemembers (Army STARRS). JAMA Psychiatry, 72(1), 49-57. doi: 10.1001/jamapsychiatry.2014.1754

King, E. A., Baldwin, D. S., Sinclair, J. M. A., Baker, N. G., Campbell, M. J., \& Thompson, C. (2001). The Wessex Recent In-Patient Suicide Study, I: Case-control study of 234 recently discharged psychiatric patient suicides. British Journal of Psychiatry, 178, 531536.

Lapierre, C. B., Schwegler, A. F., \& LaBauve, B. J. (2007). Posttraumatic stress and depression symptoms in soldiers returning from combat operations in Iraq and Afghanistan. Journal of Traumatic Stress, 20(6), 933-943.

LeardMann, C. A., Powell, T. M., Smith, T. C., Bell, M. R., Smith, B., Boyko, E. J., et al. (2013). Risk factors associated with suicide in current and former U.S. military personnel. Journal of the American Medical Association, 310(5), 496-506.

This article is protected by copyright. All rights reserved 
Luoma, J. B., Martin, C. E., \& Pearson, J. L. (2002). Contact with mental health and primary care providers before suicide: A review of the evidence. American Journal of Psychiatry, 159, 909-916.

McCarthy, J. F., Bossarte, R. M., Katz, I. R., Thompson, C., Kemp, J., Hannemann, C. M., et al. (2015). Predictive modeling and concentration of the risk of suicide: Implications for preventive interventions in the US Department of Veterans Affairs. American Journal of Public Health, 105, 1935-1942.

Nock, M. K., Borges, G., Bromet, E. J., Cha, C. B., Kessler, R. C., \& Lee, S. (2008). Suicide and suicidal behavior. Epidemiologic Reviews, 30, 133-154. doi: 10.1093/epirev/mxn002

Nock, M. K., Deming, C. A., Fullerton, C. S., Gilman, S. E., Goldenberg, M. N., Kessler, R. C., et al. (2013). Suicide among Soldiers: A review of psychosocial risk and protective factors. Psychiatry, 76, 97-125.

Nock, M. K., Hwang, I., Sampson, N. A., \& Kessler, R. C. (2010). Mental disorders, comorbidity and suicidal behavior: Results from the National Comorbidity Survey Replication. Molecular Psychiatry, 15(8), 868-876. doi: 10.1038/mp.2009.29

Nock, M. K., \& Kazdin, A. E. (2002). Examination of affective, cognitive, and behavioral factors and suicide-related outcomes in children and young adolescents. Journal of Clinical Child and Adolescent Psychology, 31(1), 48-58.

Nock, M. K., Stein, M. B., Heeringa, S. G., Ursano, R. J., Colpe, L. J., Fullerton, C. S., et al. (2014). Prevalence and correlates of suicidal behavior among soldiers: Results from the Army Study to Assess Risk and Resilience in Servicemembers (Army STARRS). JAMA Psychiatry, 71(5), 514-522.

Nock, M. K., Ursano, R. J., Heeringa, S. G., Stein, M. B., Jain, S., Raman, R., et al. (in press). Mental disorders, comorbidity, and pre-enlistment suicidal behavior among new soldiers in the U.S. Army: Results from the Army Study to Assess Risk and Resilience in Servicemembers (Army STARRS). Suicide and Life-Threatening Behavior.

Reger, M. A., Smolenski, D. J., Skopp, N. A., Metzger-Abamukang, M. J., Kang, H. K., Bullman, T. A., et al. (2015). Risk of suicide among US military service members following Operation Enduring Freedom or Operation Iraqi Freedom deployment and separation from the US military. JAMA Psychiatry, 72(6), 561-569.

This article is protected by copyright. All rights reserved 
Roalfe, A. K., Holder, R. L., \& Wilson, S. (2008). Standardisation of rates using logistic regression: A comparison with the direct method. BMC Health Services Research, 8, 275.

Rosellini, A. J., Heeringa, S. G., Stein, M. B., Ursano, R. J., Chiu, W. T., Colpe, L. J., et al. (2015). Lifetime prevalence of DSM-IV mental disorders among new soldiers in the U.S. Army: Results from the Army Study to Assess Risk and Resilience in Servicemembers (Army STARRS). Depression and Anxiety, 32, 13-24.

Schlesselman, J. J. (1982). Case-control studies: Design, conduct, analysis. New York, NY: Oxford University Press.

Schoenbaum, M., Kessler, R. C., Gilman, S. E., Colpe, L. J., Heeringa, S. G., Stein, M. B., et al. (2014). Predictors of suicide and accident death in the Army Study to Assess Risk and Resilience in Servicemembers (Army STARRS). JAMA Psychiatry, 71(5), 493-503.

Segal, D. R., \& Segal, M. W. (2004). America's military population. Population Bulletin, 59(4), $1-40$.

Shen, Y. C., Arkes, J., \& Williams, T. V. (2012). Effects of Iraq/Afghanistan deployments on major depression and substance use disorder: Analysis of active duty personnel in the US Military. American Journal of Public Health, 102(Suppl 1), S80-S87.

Smith, T. C., Ryan, M. A. K., Wingard, D. L., Slymen, D. J., Sallis, J. F., \& Kritz-Silverstein, D. (2008). New onset and persistent symptoms of post-traumatic stress disorder self reported after deployment and combat exposures: Prospective population based US military cohort study. British Medical Journal, 336(7640), 366-371.

Street, A. E., Vogt, D., \& Dutra, L. (2009). A new generation of women veterans: Stressors faced by women deployed to Iraq and Afghanistan. Clinical Psychology Review, 29, 685-694.

Ursano, R. J., Colpe, L. J., Heeringa, S. G., Kessler, R. C., Schoenbaum, M., \& Stein, M. B. (2014). The Army Study to Assess Risk and Resilience in Servicemembers (Army STARRS). Psychiatry, 72(2), 107-119.

Ursano, R. J., Heeringa, S. G., Stein, M. B., Jain, S., Raman, R., Sun, X., et al. (2015).

Prevalence and correlates of suicidal behavior among new soldiers in the US Army: Results from the Army Study to Assess Risk and Resilience in Servicemembers (Army STARRS). Depression and Anxiety, 32, 3-12.

Ursano, R. J., Kessler, R. C., Heeringa, S. G., Cox, K. L., Naifeh, J. A., Fullerton, C. S., et al. (2015). Nonfatal suicidal behaviors in U.S. Army administrative records, 2004-2009:

This article is protected by copyright. All rights reserved 
Results from the Army Study to Assess Risk and Resilience in Servicemembers (Army STARRS). Psychiatry, 78, 1-21.

Ursano, R. J., Kessler, R. C., Stein, M. B., Naifeh, J. A., Aliaga, P. A., Fullerton, C. S., et al. (2015). Suicide Attempts in the U.S. Army during the wars in Afghanistan and Iraq, 2004-2009. JAMA Psychiatry, 72(9), 917-926.

Warner, C.H., Appenzeller, G. N., Mullen, K., Warner, C. M., \& Grieger, T. (2008). Soldier attitudes toward mental health screening and seeking care upon return from combat. Military Medicine, 173, 563-569.

Warner, C. H., Appenzeller, G. N., Parker, J. R., Warner, C. M., \& Hoge, C. W. (2011). Effectiveness of mental health screening and coordination of in-theater care prior to deployment to Iraq: A cohort study. American Journal of Psychiatry, 168, 378-385.

Wells, T. S., LeardMann, C. A., Fortuna, S. O., Smith, B., Smith, T. C., Ryan, M. A. K., et al. (2010). A prospective study of depression following combat deployment in support of the wars in Iraq and Afghanistan. American Journal of Public Health, 100, 90-99.

Willett, J. B., \& Singer, J. D. (1993). Investigating onset, cessation, relapse, and recovery: why you should, and how you can, use discrete-time survival analysis to examine event occurrence. Journal of Consulting and Clinical Psychology, 61(6), 952-965.

This article is protected by copyright. All rights reserved 
Table 1. Multivariate Associations of Socio-demographic Characteristics with Suicide Ideation among Enlisted Soldiers in the U.S. Army. ${ }^{1}$

\begin{tabular}{|c|c|c|c|c|c|c|c|}
\hline Jـــ & OR & $(95 \% \mathrm{CI})$ & Cases $(N)$ & Total $(N)^{2}$ & Rate $^{3}$ & Pop $\%{ }^{4}$ & $\mathbf{S R}^{5}$ \\
\hline \multicolumn{8}{|l|}{ Gender } \\
\hline Male & 1.0 & - & 8,407 & $18,105,007$ & 557.2 & 86.7 & 550.4 \\
\hline Female & $1.6^{*}$ & $(1.5-1.7)$ & 1,825 & $2,779,025$ & 788.0 & 13.3 & 857.8 \\
\hline & & $282.7 *$ & & & & & \\
\hline \multicolumn{8}{|l|}{ Age at Army Entry } \\
\hline$<21$ & $0.7 *$ & $(0.7-0.8)$ & 6,537 & $12,842,737$ & 610.8 & 61.5 & 509.9 \\
\hline $21-24$ & 1.0 & - & 2,341 & $5,128,941$ & 547.7 & 24.6 & 688.8 \\
\hline$\geq 25$ & $1.6^{*}$ & $(1.5-1.8)$ & 1,354 & $2,912,354$ & 557.9 & 13.9 & $1,141.6$ \\
\hline & & $430.2^{*}$ & & & & & \\
\hline \multicolumn{8}{|l|}{ Current Age } \\
\hline$<21$ & $3.9^{*}$ & $(3.6-4.3)$ & 3,031 & $3,006,231$ & $1,209.9$ & 14.4 & $1,283.4$ \\
\hline $21-24$ & $2.2 *$ & $(2.0-2.4)$ & 3,606 & $6,232,206$ & 694.3 & 29.8 & 728.6 \\
\hline $25-29$ & $1.4^{*}$ & $(1.3-1.5)$ & 2,006 & $5,034,306$ & 478.2 & 24.1 & 453.5 \\
\hline $30-34$ & 1.0 & - & 843 & $2,835,043$ & 356.8 & 13.6 & 328.9 \\
\hline $35-39$ & $0.8^{*}$ & $(0.7-0.9)$ & 512 & $2,297,312$ & 267.4 & 11.0 & 274.6 \\
\hline$\geq 40$ & $0.6^{*}$ & $(0.5-0.7)$ & 234 & $1,488,034$ & 188.7 & 7.1 & 188.4 \\
\hline & & $340.4^{*}$ & & & & & \\
\hline \multicolumn{8}{|l|}{ Race/Ethnicity } \\
\hline White & 1.0 & - & 7,308 & $12,625,908$ & 694.6 & 60.5 & 656.9 \\
\hline Black & $0.7 *$ & $(0.7-0.7)$ & 1,489 & $4,573,689$ & 390.7 & 21.9 & 459.0 \\
\hline Hispanic & $0.7^{*}$ & $(0.7-0.7)$ & 958 & $2,463,158$ & 466.7 & 11.8 & 454.7 \\
\hline Asian & 0.9 & $(0.7-1.0)$ & 333 & 834,333 & 478.9 & 4.0 & 501.7 \\
\hline Other & $0.8^{*}$ & $(0.7-0.9)$ & 144 & 386,944 & 446.6 & 1.9 & 547.7 \\
\hline & & $234.7^{*}$ & & & & & \\
\hline \multicolumn{8}{|l|}{ Education } \\
\hline$<$ High School ${ }^{6}$ & $1.8^{*}$ & $(1.7-1.9)$ & 3,046 & $2,936,646$ & $1,244.7$ & 14.1 & 974.5 \\
\hline High School & 1.0 & - & 6,736 & $15,709,936$ & 514.5 & 75.2 & 521.7 \\
\hline Some College & $0.7^{*}$ & $(0.6-0.8)$ & 225 & $1,124,225$ & 240.2 & 5.4 & 359.4 \\
\hline$\geq$ College & $0.6^{*}$ & $(0.5-0.7)$ & 225 & $1,113,225$ & 242.5 & 5.3 & 304.3 \\
\hline
\end{tabular}

This article is protected by copyright. All rights reserved 


$$
\chi_{3}^{2} \quad 842.8^{*}
$$

Marital Status

$\begin{array}{lccccccc}\text { Never Married } & 1.0 & (1.0-1.1) & 5,384 & 8,258,784 & 782.3 & 39.5 & 594.7 \\ \text { Currently Married } & 1.0 & - & 4,593 & 11,718,593 & 470.3 & 56.1 & 584.4 \\ \text { Previously Married } & 0.9 & (0.8-1.0) & 255 & 906,655 & 337.5 & 4.3 & 520.5 \\ & \chi_{2}^{2} & & 5.3 & & & & \\ \text { Total }\end{array}$

${ }^{1}$ The sample of enlisted soldiers ( $\mathrm{n}=10,232$ cases, 104,369 control person-months) is a subset of the total sample ( $\mathrm{n}=135,425$ person-months) from the Army STARRS Historical Administrative Data Study (HADS) that includes all Regular Army soldiers (i.e., excluding those in the U.S. Army National Guard and Army Reserve) with suicide ideation in their administrative records during the years 2006-2009, plus a 1:200 stratified probability sample of all other active duty Regular Army person-months in the population exclusive of soldiers with suicide ideation or other non-fatal suicidal event (e.g., suicide attempt) and person-months in which the soldier died (i.e., suicides, combat deaths, homicides, and deaths due to other injuries or illnesses). All records in the 1:200 sample were assigned a weight of 200 to adjust for the under-sampling of months not associated with suicide ideation. The analysis included a dummy predictor variable for calendar month and year to control for secular trends.

${ }^{2}$ Total includes both cases (i.e., soldiers with suicide ideation) and control person-months.

${ }^{3}$ Rate per 100,000 person-years, calculated based on $n_{1} / n_{2}$, where $n_{1}$ is the unique number of soldiers within each category and $\mathrm{n}_{2}$ is the annual number of person-years, not person-months, in the population ( $\mathrm{n}=3.08$ million). ${ }^{4}$ Pop \% $=$ Percent of the Regular Army enlisted population.

${ }^{5} \mathrm{SR}=$ Standardized risk estimate (suicide ideators per 100,000 person-years) was calculated assuming other predictors were at their sample-wide means.

${ }^{6}<$ High School includes: General Educational Development credential (GED), home study diploma, occupational program certificate, correspondence school diploma, high school certificate of attendance, adult education diploma, and other non-traditional high school credentials.

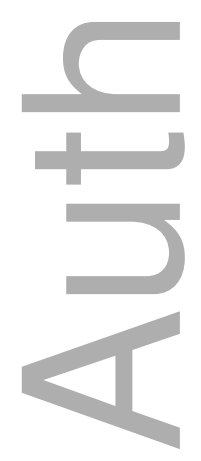


Table 2. Multivariate Associations of Socio-demographic Characteristics with Suicide Ideation among Officers in the U.S. Army. ${ }^{1}$

\begin{tabular}{|c|c|c|c|c|c|c|c|}
\hline ك & OR & $(95 \% \mathrm{CI})$ & Cases $(N)$ & Total $(N)^{2}$ & Rate $^{3}$ & Pop $\%^{4}$ & $\mathbf{S R}^{5}$ \\
\hline \multicolumn{8}{|l|}{ Gender } \\
\hline Male & 1.0 & - & 172 & $3,489,772$ & 59.1 & 84.7 & 58.1 \\
\hline Female & $2.3^{*}$ & $(1.7-3.1)$ & 62 & 628,462 & 118.4 & 15.3 & 131.2 \\
\hline & & $27.1^{*}$ & & & & & \\
\hline \multicolumn{8}{|l|}{ Age at Army Entry } \\
\hline$<21$ & $1.8 *$ & $(1.3-2.4)$ & 67 & 866,867 & 92.7 & 21,0 & 99.2 \\
\hline $21-24$ & 1.0 & - & 115 & $2,407,915$ & 57.3 & 58.5 & 55.9 \\
\hline \multirow[t]{2}{*}{$\geq 25$} & 1.3 & $(0.9-1.9)$ & 52 & 843,452 & 74.0 & 20.5 & 74.5 \\
\hline & & $12.5^{*}$ & & & & & \\
\hline \multicolumn{8}{|l|}{ Current Age } \\
\hline$\leq 24$ & 0.9 & $(0.5-1.6)$ & 17 & 372,017 & 54.8 & 9.0 & 68.3 \\
\hline $25-29$ & 0.9 & $(0.6-1.4)$ & 51 & 899,651 & 68.0 & 21.8 & 70.8 \\
\hline $30-34$ & 1.0 & - & 54 & 834,254 & 77.7 & 20.3 & 75.5 \\
\hline $35-39$ & 1.2 & $(0.8-1.7)$ & 65 & 850,065 & 91.8 & 20.6 & 88.3 \\
\hline$\geq 40$ & $0.6^{*}$ & $(0.4-0.9)$ & 47 & $1,162,247$ & 48.5 & 28.2 & 46.5 \\
\hline$\chi_{4}^{2}$ & & $11.1^{*}$ & & & & & \\
\hline
\end{tabular}

\section{Race/Ethnicity}

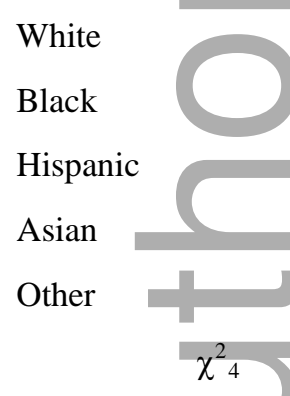

$\begin{array}{lc}1.0 & - \\ 0.6^{*} & (0.4-1.0) \\ 1.4 & (0.9-2.1) \\ 0.6 & (0.3-1.5) \\ 0.7 & (0.4-1.3) \\ & 9.2\end{array}$

$\begin{array}{ccccc}172 & 2,998,572 & 68.8 & 72.8 & 72.8 \\ 26 & 542,426 & 57.5 & 13.2 & 46.9 \\ 22 & 244,822 & 107.8 & 5.9 & 98.8 \\ 9 & 202,209 & 53.4 & 4.9 & 49.5 \\ 5 & 103,205 & 46.1 & 3.2 & 45.3\end{array}$

\section{Education}

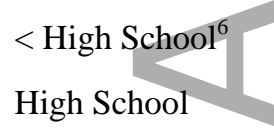

Some College

$\geq$ College

$$
\chi_{3}^{2}
$$

$1.1 \quad(0.3-4.1)$

1.0

1.0

$1.8^{*}$

$(0.4-2.7)$

(1.0-3.4)

5.9

$\begin{array}{cccc}70,003 & 51.4 & 1.7 & 44.6 \\ 267,812 & 53.8 & 6.5 & 39.9 \\ 142,606 & 50.5 & 3.5 & 39.9 \\ 3,637,813 & 70.3 & 88.3 & 73.1\end{array}$

$3,637,813$
3

12

6

213

(1)

(n)




\section{Marital Status}

\begin{tabular}{lccccccc} 
Never Married & $0.6^{*}$ & $(0.4-0.9)$ & 43 & 988,843 & 52.2 & 24.0 & 46.1 \\
Currently Married & 1.0 & - & 173 & $2,945,373$ & 70.5 & 71.5 & 74.2 \\
Previously Married & 1.5 & $(0.9-2.4)$ & 18 & 184,018 & 117.4 & 4.5 & 107.5 \\
& & $9.1^{*}$ & & & & & \\
\multicolumn{1}{l}{ Total } & - & - & 234 & $4,118,234$ & 68.2 & 100.0 & - \\
\hline
\end{tabular}

${ }^{1}$ The sample of officers ( $\mathrm{n}=234$ cases, 20,590 control person-months) is a subset of the total sample $(\mathrm{n}=135,425$ person-months) from the Army STARRS Historical Administrative Data Study (HADS) that includes all Regular Army soldiers (i.e., excluding those in the U.S. Army National Guard and Army Reserve) with suicide ideation in their administrative records during the years 2006-2009, plus a 1:200 stratified probability sample of all other active duty Regular Army person-months in the population exclusive of soldiers with suicide ideation or other non-fatal suicidal event (e.g., suicide attempt) and person-months in which the soldier died (i.e., suicides, combat deaths, homicides, and deaths due to other injuries or illnesses). All records in the 1:200 sample were assigned a weight of 200 to adjust for the under-sampling of months not associated with suicide ideation. The analysis included a dummy predictor variable for calendar month and year to control for secular trends.

${ }^{2}$ Total includes both cases (i.e., soldiers with suicide ideation) and control person-months.

${ }^{3}$ Rate per 100,000 person-years, calculated based on $n_{1} / n_{2}$, where $n_{1}$ is the unique number of soldiers within each category and $\mathrm{n}_{2}$ is the annual number of person-years, not person-months, in the population $(\mathrm{n}=3.08$ million). ${ }^{4}$ Pop $\%=$ Percent of the Regular Army officer population.

${ }^{5} \mathrm{SR}=$ Standardized risk estimate (suicide ideators per 100,000 person-years) was calculated assuming other predictors were at their sample-wide means.

${ }^{6}<$ High School includes: General Educational Development credential (GED), home study diploma, occupational program certificate, correspondence school diploma, high school certificate of attendance, adult education diploma, and other non-traditional high school credentials.

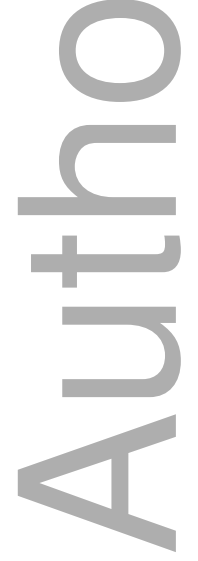


Table 3. Multivariate Associations of Time in Service, Deployment Status, and Time Since Most Recent Mental Health Diagnosis with Suicide Ideation among Enlisted Soldiers in the U.S. Army. ${ }^{1,2}$

\begin{tabular}{|c|c|c|c|c|c|c|c|}
\hline 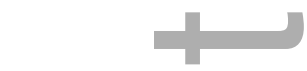 & OR & $(95 \% \mathrm{CI})$ & Cases $(N)$ & Total $(N)^{3}$ & Rate $^{4}$ & Pop $\%^{5}$ & $\mathbf{S R}^{6}$ \\
\hline \multicolumn{8}{|l|}{ I. Time in Service ${ }^{1}$} \\
\hline $1-2$ years & $2.2 *$ & $(2.0-2.4)$ & 5,374 & $5,792,174$ & $1,113.4$ & 27.7 & 902.9 \\
\hline $3-4$ years & $1.4^{*}$ & $(1.3-1.5)$ & 2,336 & $4,622,536$ & 606.4 & 22.1 & 575.2 \\
\hline 5-10 years & 1.0 & - & 1,842 & $5,826,042$ & 379.4 & 27.9 & 413.6 \\
\hline$>10$ years & $0.6^{*}$ & $(0.5-0.7)$ & 680 & $4,643,280$ & 175.7 & 22.2 & 231.6 \\
\hline \multicolumn{8}{|c|}{$550.0^{*}$} \\
\hline \multicolumn{8}{|c|}{ II. Deployment Status ${ }^{1}$} \\
\hline Never deploy & $3.9^{*}$ & $(3.6-4.2)$ & 5,900 & $7,557,900$ & 936.8 & 36.2 & 733.2 \\
\hline Currently depl & 1.0 & - & 826 & $5,234,426$ & 189.4 & 25.1 & 193.2 \\
\hline Previously depl & $3.5^{*}$ & $(3.2-3.8)$ & 3,506 & $8,091,706$ & 519.9 & 38.7 & 690.2 \\
\hline \multicolumn{8}{|c|}{$1,301.7^{*}$} \\
\hline \multicolumn{8}{|c|}{ III. Times Since Most Recent Mental Health Diagnosis ${ }^{1}$} \\
\hline No Diagnosis & 1.0 & - & 4,203 & $15,163,403$ & 332.6 & 72.6 & 313.4 \\
\hline 1 Month & $14.4 *$ & $(13.7-15.0)$ & 3,564 & 914,564 & $4,676.3$ & 4.4 & $4,638.9$ \\
\hline 2-3 Months & $5.0^{*}$ & $(4.7-5.4)$ & 886 & 664,086 & $1,601.0$ & 3.2 & $1,598.9$ \\
\hline 4-12 Month & $2.5^{*}$ & $(2.4-2.7)$ & 967 & $1,523,567$ & 761.6 & 7.3 & 812.7 \\
\hline$\geq 13$ Months & $1.3^{*}$ & $(1.2-1.4)$ & 612 & $2,618,412$ & 280.5 & 12.5 & 413.4 \\
\hline$\chi_{4}^{2}$ & & $691.1^{*}$ & & & & & \\
\hline
\end{tabular}

${ }^{1}$ The sample of enlisted soldiers ( $\mathrm{n}=10,232$ cases, 104,369 control person-months) is a subset of the total sample ( $n=135,425$ person-months) from the Army STARRS Historical Administrative Data Study (HADS) that includes all Regular Army soldiers (i.e., excluding those in the U.S. Army National Guard and Army Reserve) with suicide ideation in their administrative records during the years 2006-2009, plus a 1:200 stratified probability sample of all other active duty Regular Army person-months in the population exclusive of soldiers with suicide ideation or other non-fatal suicidal event (e.g., suicide attempt) and person-months in which the soldier died (i.e., suicides, combat deaths, homicides, and deaths due to other injuries or illnesses). All records in the 1:200 sample were assigned a weight of 200 to adjust for the under-sampling of months not associated with suicide ideation.

${ }^{2}$ In separately examining the effects of time in service, deployment status, and mental health diagnosis, we controlled for basic socio-demographic variables (gender, age at entry into the Army, current age, race, education,

This article is protected by copyright. All rights reserved 
marital status). All analyses also included a dummy predictor variable for calendar month and year to control for secular trends.

${ }^{3}$ Total includes both cases (i.e., soldiers with suicidal ideation) and control person-months.

${ }^{4}$ Rate per 100,000 person-years, calculated based on $n_{1} / n_{2}$, where $n_{1}$ is the unique number of soldiers within each category and $\mathrm{n}_{2}$ is the annual number of person-years, not person-months, in the population ( $\mathrm{n}=3.08$ million). ${ }^{5}$ Pop \% = Percent of the Regular Army enlisted population.

${ }^{6} \mathrm{SR}=$ Standardized risk estimate (suicide ideators per 100,000 person-years) was calculated assuming other predictors were at their sample-wide means.

${ }^{7}<$ High School includes: General Educational Development credential (GED), home study diploma, occupational program certificate, correspondence school diploma, high school certificate of attendance, adult education diploma,

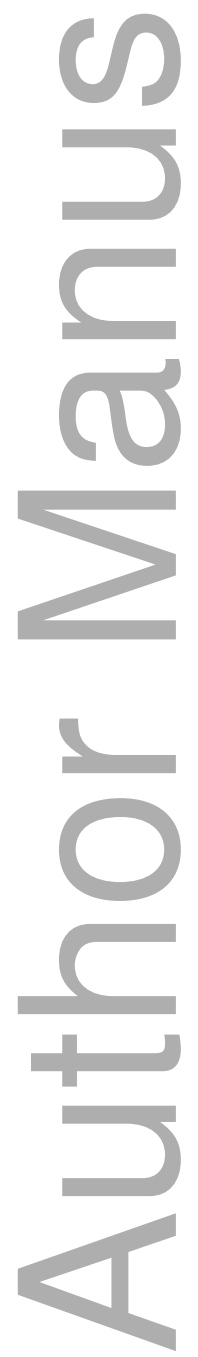


Table 4. Multivariate Associations of Time in Service, Deployment Status, and Time Since Most Recent Mental Health Diagnosis with Suicide Ideation among Officers in the U.S. Army.,

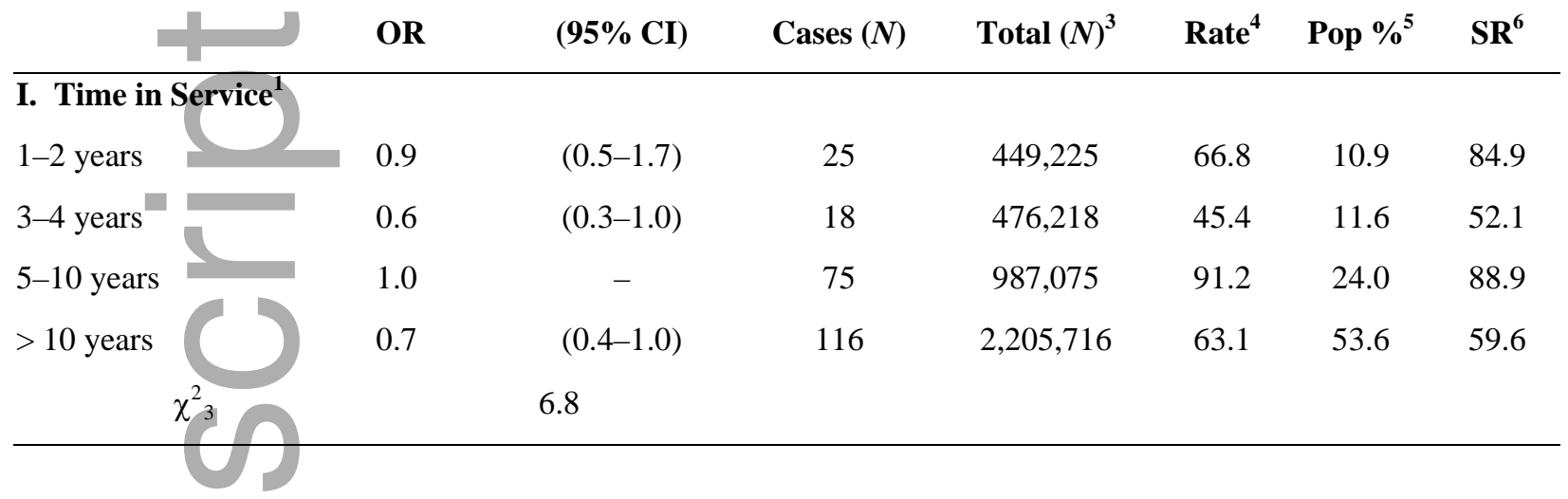

\section{Deployment Status ${ }^{1}$}

\begin{tabular}{rlcccccc} 
Never deployed & 1.3 & $(0.8-1.9)$ & 69 & $1,265,469$ & 65.4 & 30.7 & 63.2 \\
Currently deployed & 1.0 & - & 37 & 867,837 & 51.2 & 21.1 & 52.2 \\
Previously deployed & $1.5^{*}$ & $(1.0-2.1)$ & 128 & $1,984,928$ & 77.4 & 48.2 & 78.5 \\
$\chi^{2} 2$ & & 4.3 & & & & & \\
\hline
\end{tabular}

\section{Time Since Most Recent Mental Health Diagnosis ${ }^{1}$}

\begin{tabular}{llcccccc} 
No Diagnosis & 1.0 & - & 63 & $3,381,463$ & 22.4 & 82.1 & 21.9 \\
1 Month & $74.0^{*}$ & $(52.9-103.6)$ & 98 & 80,298 & $1,464.5$ & 1.9 & $1,632.0$ \\
2-3 Months & $13.4^{*}$ & $(7.7-23.1)$ & 17 & 74,017 & 275.6 & 1.8 & 303.6 \\
4-12 Months & $10.5^{*}$ & $(6.7-16.3)$ & 30 & 167,030 & 215.5 & 4.1 & 236.1 \\
$\geq 13$ Months & $3.8^{*}$ & $(2.4-6.0)$ & 26 & 415,426 & 75.1 & 10.1 & 83.2 \\
\multicolumn{1}{c}{} & & & & & & & \\
\hline
\end{tabular}

${ }^{1}$ The sample of officers ( $\mathrm{n}=234$ cases, 20,590 control person-months) is a subset of the total sample ( $\mathrm{n}=135,425$ person-months) from the Army STARRS Historical Administrative Data Study (HADS) that includes all Regular Army soldiers (i.e., excluding those in the U.S. Army National Guard and Army Reserve) with suicide ideation in their administrative records during the years 2006-2009, plus a 1:200 stratified probability sample of all other active duty Regular Army person-months in the population exclusive of soldiers with suicide ideation or other non-fatal suicidal event (e.g., suicide attempt) and person-months in which the soldier died (i.e., suicides, combat deaths, homicides, and deaths due to other injuries or illnesses). All records in the 1:200 sample were assigned a weight of 200 to adjust for the under-sampling of months not associated with suicide ideation.

${ }^{2}$ In separately examining the effects of time in service, deployment status, and mental health diagnosis, we controlled for the basic socio-demographic variables reported in Tables 1 and 2 (gender, age at entry into the Army, 
current age, race, education, marital status). All analyses also included a dummy predictor variable for calendar month and year to control for secular trends.

${ }^{3}$ Total includes both cases (i.e., soldiers with suicidal ideation) and control person-months.

${ }^{4}$ Rate per 100,000 person-years, calculated based on $n_{1} / n_{2}$, where $n_{1}$ is the unique number of soldiers within each category and $\mathrm{n}_{2}$ is the annual number of person-years, not person-months, in the population ( $\mathrm{n}=3.08$ million). ${ }^{5} \mathrm{Pop} \%=$ Percent of the Regular Army officer population.

${ }^{6} \mathrm{SR}=$ Standardized risk estimate (suicide ideators per 100,000 person-years) was calculated assuming other predictors were at their sample-wide means.

${ }^{7}<$ High School includes: General Educational Development credential (GED), home study diploma, occupational program certificate, correspondence school diploma, high school certificate of attendance, adult education diploma, and other non-traditional high school credentials.

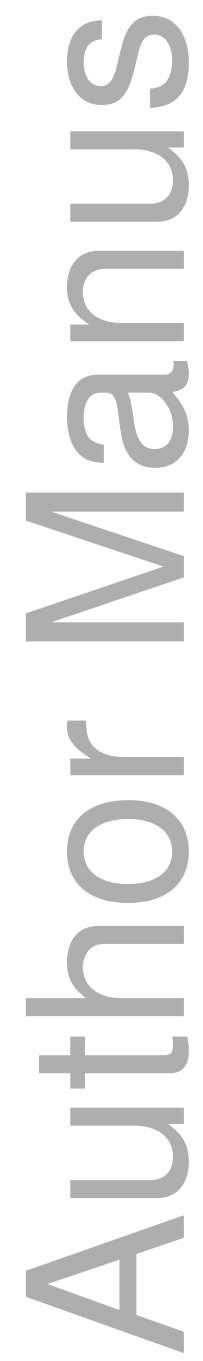


Figure 1. Risk of Suicide Ideation among Enlisted Soldiers and Officers by Month Since Entering the Army. ${ }^{1}$

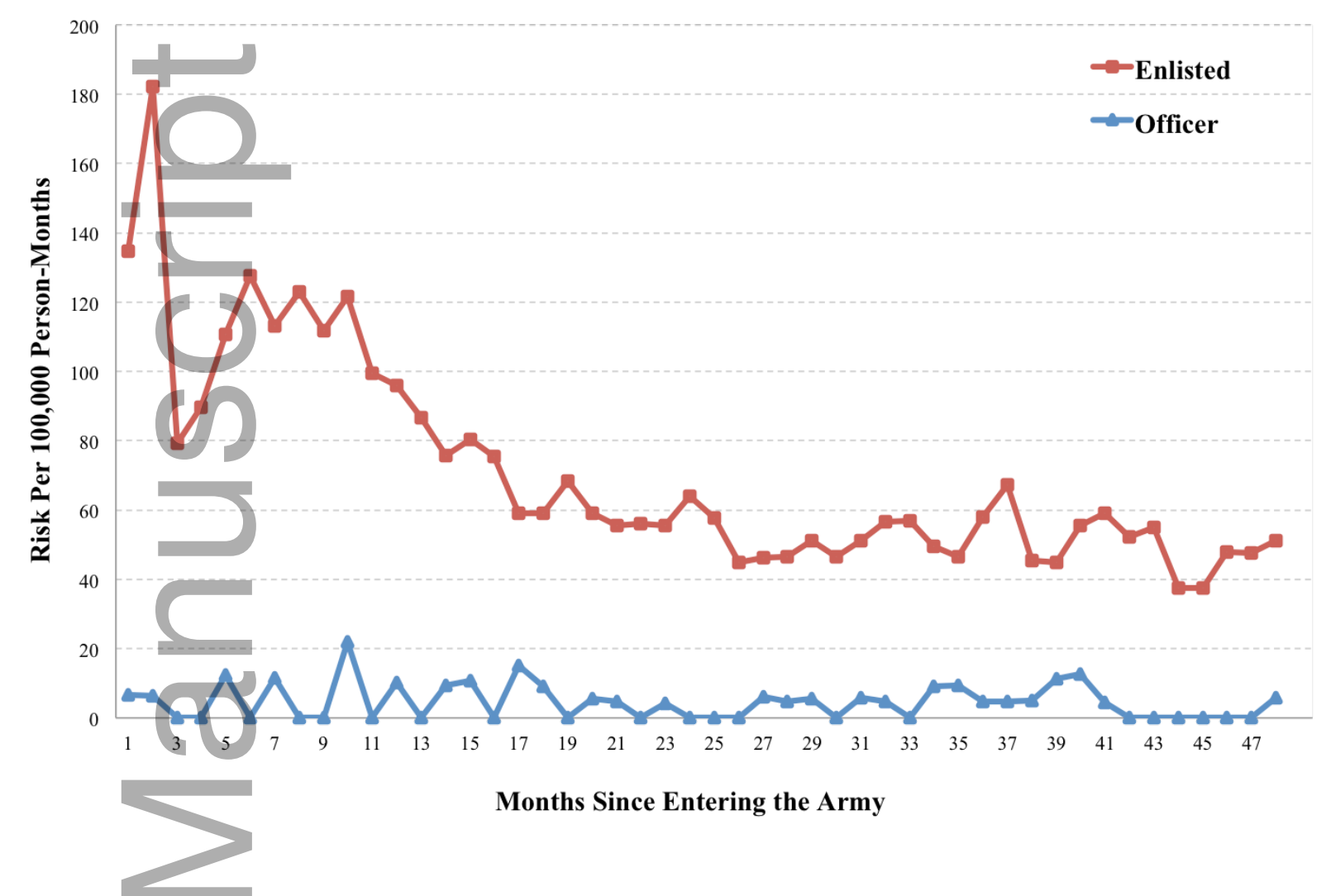

${ }^{1}$ The sample of enlisted soldiers ( $n=10,232$ cases, 104,369 control person-months) and officers ( $n=234$ cases, 20,590 control person-months) is from the Army STARRS Historical Administrative Data Study (HADS). It includes all Regular Army soldiers (i.e., excluding those in the U.S. Army National Guard and Army Reserve) with suicide ideation in their administrative records during the years 2006-2009, plus a 1:200 stratified probability sample of all other active duty Regular Army person-months in the population exclusive of soldiers with suicide ideation or other non-fatal suicidal event (e.g., suicide attempt) and person-months in which the soldier died (i.e., suicides, combat deaths, homicides, and deaths due to other injuries or illnesses). All records in the 1:200 sample were assigned a weight of 200 to adjust for the under-sampling of months not associated with suicide ideation.

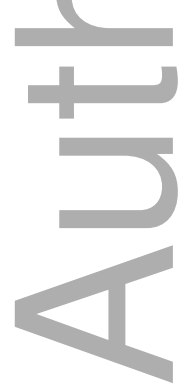




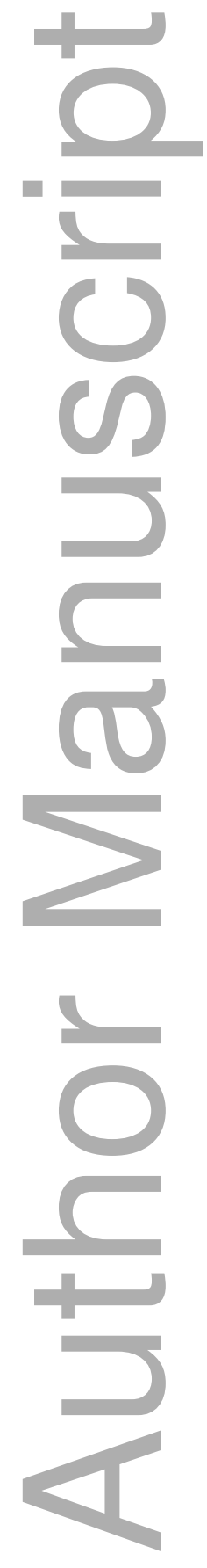

This article is protected by copyright. All rights reserved 